\title{
LA INFLUENCIA PLATÓNICA \\ EN LA CONCEPCIÓN ARISTOTÉLICA DEL "SÍ MISMO" EN EL PROTRÉPTICO Y EN LA ÉTICA NICOMAQUEA
}

\author{
DIEGO TABAKIAN ${ }^{1}$
}

\begin{abstract}
RESUMEN: A pesar de las diferencias palpables en las antropologías platónica y aristotélica, ambos filósofos afirman la identidad del "sí mismo" con el noûs. El objeto de este trabajo consiste en mostrar la influencia platónica en la obra aristotélica en torno a la noción de "sí mismo", tanto en su período académico como en su pensamiento posterior. A grandes rasgos, el maestro desarrolló dos concepciones diferentes del sí mismo: en el Alcibíades mayor identifica netamente el sí mismo con el intelecto, mientras que en la República lo identifica con cada parte del alma y con la totalidad del alma gobernada por una parte específica. Por su parte, el discípulo reproduce parcialmente la primera concepción platónica del "sí mismo" en el Protréptico, mientras que adopta los lineamientos centrales de la segunda en Ética Nicomaquea IX. 8-9. Aunque el Estagirita se distancia de su maestro en algunos matices, sigue su ideario ético-antropológico al sostener que la realización de la vida contemplativa presupone que el intelecto gobierne la conducta humana.
\end{abstract}

Palabras clave: Platón - Aristóteles - sí mismo - alma.

ABSTRACT: Despite the palpable differences in Platonic and Aristotelian anthropologies, both philosophers affirm the identity of the self with noûs. The purpose of this paper is to show the Platonic influence on the Aristotelian work on the notion of self, both in his Academic period and in his later thought. Broadly speaking, the master developed two different conceptions of the self: in the Alcibiades major he clearly identifies the self with the intellect, while in the Republic he

\footnotetext{
${ }^{1}$ AGENCIA-UBA-USAL. E-mail: diegotabakian@gmail.com Fecha de recepción: 19/10/2021; fecha de aceptación: 9/12/2021. DOI: https://doi.org/10.46553/sty.30.30.2021.p124-136
}

Stylos. 2021; 30 (30); pp. 124-136; ISSN: 0327-8859; E-ISSN: 2683-7900 
identifies it with each part of the soul and with the totality of the soul governed by a specific part. The disciple partially reproduces the first Platonic conception of the "self" in the Protrepticus, while he adopts the central lines of the second in Nicomachean Ethics IX. 8-9. Although the Stagirite distances himself from his master in some nuances, he follows the Platonic ethical-anthropological ideal in maintaining that the realization of the contemplative life presupposes that the intellect governs human behavior.

Keywords: Plato - Aristotle - Self - Soul.

A pesar de que Platón y Aristóteles sostienen concepciones antropológicas diferentes, ambos afirman la identidad del "sí mismo" humano con el noûs. El objeto del presente trabajo consiste en mostrar la influencia platónica en la obra aristotélica en torno a la noción de "sí mismo" tanto en su período académico como en su pensamiento posterior. ${ }^{2}$ A su vez, procuraremos mostrar algunos matices en los que el Estagirita se distancia de su maestro.

A lo largo de sus diálogos, Platón sostuvo diferentes visiones sobre el alma, el intelecto, y la relación de estos con el cuerpo, conceptualizando, por lo menos, dos concepciones diferentes sobre el "sí mismo". En esta línea, en el Alcibíades mayor, Platón sostuvo que el ser humano es un compuesto de cuerpo y alma, pero afirma que el verdadero "sí mismo" es su alma, que se distingue del cuerpo y de otras posesiones externas. El alma manda y gobierna sobre el cuerpo, que constituye una mera posesión e instrumento (124b-135e). En otras palabras, así como los bienes materiales constituyen instrumentos del cuerpo, este constituye una herramienta del alma. Si bien en este diálogo Platón no distingue expresamente entre partes del alma, sí afir-

\footnotetext{
${ }^{2}$ En TABAKIAN (2017) examino la influencia de Alcibíades I y Rep. IV, VIII y IX en la concepción aristotélica del conocimiento y del cuidado de sí tal como es desarrollada en el tratamiento de la amistad en EN IX.
}

Stylos. 2021; 30 (30); pp. 124-136; ISSN: 0327-8859; E-ISSN: 2683-7900 
ma que nuestro "sí mismo" no se identifica, en rigor, con la totalidad del alma sino con una parte suya, la inteligencia. ${ }^{3}$

El contexto de estas afirmaciones son las enseñanzas que Sócrates pretende inculcar al joven Alcibíades en torno al cuidado y al conocimiento de sí: cuidamos de nosotros mismos cuando cuidamos de nuestra alma, y conocemos lo más propio y constitutivo de nosotros, al conocer la parte superior y divina del alma, la parte racional. Platón plantea el autoconocimiento mediante la potente metáfora del espejo (133b-c), en la que se establece un paralelismo entre los ojos y el alma: para conocerse a sí mismos, ambos requieren una suerte de espejo en el cual observar su reflejo (132d-e). Así como el ojo se ve a sí mismo en la mejor parte del ojo del prójimo (la pupila), el alma se conoce a sí misma cuando contempla la mejor parte del alma del otro, el intelecto (133b-c).

El corolario de la metáfora del espejo es que únicamente podemos conocer nuestro sí mismo a partir de la contemplación de otro sí mismo, que oficia de reflejo. El autoconocimiento es esencialmente mediato: conozco lo más propio de mí mismo al contemplarlo en otro semejante. Ahora bien, para que esta mediación sea posible, es necesario que mi sí mismo y el del otro sean esencialmente idénticos, de lo contrario no podría conocerme a mí mismo a partir de la contemplación del sí mismo ajeno: lo que ambos compartimos no son características accidentales e individuales, sino nuestra esencia, es decir, nuestro intelecto. ${ }^{4}$

Ahora bien, el filósofo desarrolla una segunda concepción del "sí mismo" en los diálogos donde avanza sobre la constitución interna del alma. Por cuestiones de extensión nos centraremos en la conceptualización del alma tripartita en República (IV. 436a8-439e3, 439e3-441c2). Aquí Platón no identifica netamente el "sí mismo" con la parte racional, sino que atribuye

\footnotetext{
${ }^{3}$ Cf.. A. J. CAPpelletti (1992: 31).

${ }^{4}$ Como señala RIDER (2011:13), la relevancia del autoconocimiento para la política consiste en que no tiene por objeto hechos contingentes sobre la propia personalidad o sobre los bienes personales, sino sobre cualidades compartidas universalmente por todos los hombres. Siguiendo a ANNAS (1985), podemos sostener que Platón excluye el cuerpo y el resto del alma (memorias, personalidad, etc.) del "sí mismo" porque el autoconocimiento no tiene por objeto las características particulares y personales de cada uno, sino lo impersonal y lo común a todos los seres humanos, esto es, la naturaleza humana universal.
}

Stylos. 2021; 30 (30); pp. 124-136; ISSN: 0327-8859; E-ISSN: 2683-7900 
dicho título a cada parte, y al alma en su conjunto de acuerdo con un sentido amplio y otro estricto de "sí mismo".

"¿Y no es verdad que "ser dueño de sí mismo" es una expresión ridícula? Quien sea dueño de sí mismo será al mismo tiempo esclavo de sí mismo, y el que sea su propio esclavo será también su amo, puesto que todas estas expresiones se refieren a la misma persona" $(430 \mathrm{e}-431 \mathrm{a}) .^{5}$

Es evidente que un mismo sujeto no estará en disposición de hacer o sufrir al mismo tiempo cosas contrarias en la misma parte de sí y con respecto al mismo objeto, de suerte que si encontramos aquí efectos contrarios, reconocemos que no proceden de una misma parte sino de varias $(436 \mathrm{~b}-\mathrm{c}) .{ }^{6}$

Aunque el alma se encuentre compuesta de tres partes, no deja de ser una, ya que, desde el punto de vista de la acción, el alma se conduce en su totalidad sin contradicciones siguiendo los fines establecidos por la parte que se erige como conductora del conjunto. ${ }^{7}$ Si bien las diferentes partes del alma tienden a objetos distintos, y pueden contradecirse entre sí, al momento de actuar se ordenan necesariamente bajo la conducción de una parte rectora. En otras palabras, racionalidad (tò epithymetikón), apetitos (tò epithymetikón) e impulsividad (tò thymoeidés) abarcan diferentes funciones de una misma alma y, en ese sentido, constituyen tres aspectos de un mismo ser humano, por lo que cada una puede denominarse "sí mismo". Cada parte persigue fines distintos $y$, en la medida en que puede asumir la conducción de toda el alma, puede establecer sus propios fines como las metas del alma en su conjunto.

\footnotetext{
${ }^{5}$ Todas las traducciones de la República corresponden a CAMARERO (2003).

${ }^{6}$ Sobre el principio de no-contradicción platónico, Cf. Robinson (1971), STALley (1975), SIEWERT (2001) y FERRARI (2007).

${ }^{7}$ Sobre la unidad del alma tripartita y los ordenamientos del alma seguimos a BIEDA (2015: 19-22), quien habla de "unidad cuantitativa" y "unidad cualitativa" del alma.
}

Stylos. 2021; 30 (30); pp. 124-136; ISSN: 0327-8859; E-ISSN: 2683-7900 
En esta línea, la dinámica interna entre las partes racional, impulsiva y apetitiva da lugar a tres posibles órdenes o configuraciones de la totalidad del alma que se derivan del predominio de una parte por sobre las demás. ${ }^{8}$ Podemos hablar de almas "aristocráticas", "timocráticas" o "tiránicas" dependiendo del "sí mismo" que gobierne el alma, puesto que cada parte configura al alma en dirección de sus propios fines. Ahora bien, no es que el gobierno de una parte suprime los otros aspectos del alma, sino que las partes subordinadas cumplen sus funciones siguiendo el dictado de la parte rectora: de este modo, en las almas tiránicas gobierna el apetito, y los aspectos racional e impulsivo se limitan a obedecer su comando. En contraposición, en el alma aristocrática, la racionalidad controla los deseos del apetito, y se vale del auxilio de la parte impulsiva para lograr el gobierno del alma en su conjunto.

Platón contrapone el gobierno de la racionalidad a la conducción de las partes irracionales: ${ }^{9}$ únicamente el imperio de la parte racional constituye un alma justa, en armonía, y que tiende hacia la verdad (586e-587a). Por el contrario, cuando gobierna una parte a la que no le corresponde lícitamente mandar, tiene lugar una configuración del alma que se caracteriza por la desarmonía, la injusticia y el vicio moral (444b, 587a-b).

Esta concepción de la justicia y la armonía psíquica (443d-e) presupone una división de tareas natural en el alma humana que puede no cumplirse. En efecto, la racionalidad es caracterizada como la parte que conoce la verdad, distingue entre el bien y el mal y, en función de ello, debe gobernar la totalidad del alma (441e-442c, 581b, 582a). Se trata de la parte que calcula racionalmente y que puede reconocer lo bueno y lo conveniente para cada

\footnotetext{
${ }^{8}$ Para Fierro (2007: 72), “en la teoría del alma se distinguen en Rep. 6.485d6-8 dos «corrientes de deseo» fundamentales de la misma, así como también, en el Libro 4, tres distintos «aspectos» (eíde) o «partes» (mére) con sus deseos propios o constitutivos, y, en los Libros 8 y 9 , las formas en que estos aspectos pueden combinarse, dando por resultado diversas estructuras psíquicas".

${ }_{9}^{9}$ De acuerdo con FIERRO (2007: 75), la contraposición sobre la cual se deduce la tripartición del alma es la contraposición entre deseos: "las dos corrientes principales de deseo descritas anteriormente son las siguientes: por un lado, la corriente de la razón que fluye hacia la verdad y el verdadero bien; por el otro, la corriente de los apetitos que se desliza hacia los placeres y lo cambiante".
}

Stylos. 2021; 30 (30); pp. 124-136; ISSN: 0327-8859; E-ISSN: 2683-7900 
parte, y para el conjunto del alma (442c5-8). Puesto que conoce el bien real, se opone a los deseos irracionales del alma apetitiva, la cual se caracteriza por procurar satisfacer sus deseos desentendiéndose de cualquier criterio moral (438b-439e). La parte apetitiva desea todo aquello que satisface necesidades naturales (437b-437e), y también la riqueza (581a), pero el modo en que procura su satisfacción no sigue criterios racionales y morales, sino los impulsos del propio deseo, que considera es "bueno" todo aquello que lo satisface. ${ }^{10}$ Otra falencia de la parte apetitiva es que es insaciable (442a-b, 586e-587a), es decir, carece de límites y no es capaz de auto limitarse. Por estas razones, la parte apetitiva se equivoca en la consecución del bien real y suele dar con males que aparenta ser bienes.

En este contexto, no se destaca el intelecto como la parte esencial del hombre porque la finalidad es explicar los órdenes del alma que presupone la prâxis de los individuos, es decir, la configuración anímica que determina un estilo de vida. Puesto que el alma puede encontrarse en la verdad o en la falsedad (según gobierne la racionalidad o las partes irracionales), sostenemos que en la República, Platón concibió un "sí mismo" verdadero y un "sí mismo" falso en el ámbito de la prâxis.

"Por lo tanto, cuando el alma toda obedece a la parte filosófica y no se suscita en ella rebelión alguna, cada una de sus partes se mantiene dentro de los límites de sus funciones y practica de tal modo la justicia, y además goza de los placeres que les son propios es decir, de los mejores y, en la medida de lo posible, los más verdaderos" (586e-587a).

Tanto los individuos aristocráticos como los timocráticos, y tiránicos poseen tres sí mismos (entendidos como partes del alma) y un "sí mismo" (entendido como la totalidad del alma conducida por una parte rectora). Sin embargo, Platón concibió que únicamente el orden racional del alma es aquel que garantiza la justicia, la armonía (la ausencia de conflictos internos en el alma), el acceso a la verdad y, por lo tanto, la realización del bien real en el plano de la acción moral (583a-b). En otras palabras, el "sí mismo"

${ }^{10}$ Cf. BIEDA (2015: 4-8).

Stylos. 2021; 30 (30); pp. 124-136; ISSN: 0327-8859; E-ISSN: 2683-7900 
verdadero del ser humano se identifica con la totalidad del alma gobernada por el intelecto. Por el contrario, el "sí mismo" falso consiste en la totalidad del alma gobernada por los aspectos irracionales.

A pesar de las diferencias palpables entre el Alcibíades y la República, ambos planteos no son incompatibles: conocer el verdadero "sí mismo" del hombre consiste en conocer la parte del alma que esencialmente constituye la naturaleza humana, y que debe constituirse en la parte rectora del hombre. El ser humano puede vivir no siendo auténticamente sí mismo si configura la totalidad de su alma de acuerdo con lo que no constituye verdaderamente su esencia, esto es, las partes irracionales del alma.

En el Protréptico, el joven Aristóteles sostiene la bipartición del alma en partes racional e irracional (Fr. 23, 24), en línea con el planteo de República, pero sigue al Alcibíades mayor al identificar el "sí mismo" con el intelecto (Fr. 28, 61 y 62), la facultad que, en este contexto, se caracteriza por la aprehensión de los primeros principios y causas de la naturaleza (Fr. 32-37, 48).

"La naturaleza en su totalidad, como si estuviera dotada de razón, no hace nada al azar, sino con vistas a algo, y desterrando el azar, la naturaleza atiende al fin más incluso que las artes, porque también las artes eran imitaciones de la naturaleza. Al estar constituido el hombre por naturaleza de alma y cuerpo, siendo el alma mejor que el cuerpo y ordenándose siempre lo peor para servir con vistas a lo mejor, también el cuerpo existe con vistas al alma. Ahora bien, en el alma una parte estaba dotada de razón y otra carecía de ella, que era precisamente la peor, de manera que la parte irracional se ordena con vistas a la que está dotada de razón. Ahora bien, el intelecto radica en la que está dotada de razón, de forma que la demostración nos obliga a afirmar que todo <en el hombre> existe con vistas al intelecto (Fragmento 23). ${ }^{11}$

En línea con la concepción instrumentalista del cuerpo del Alcibíades mayor, Aristóteles afirma que el cuerpo y el alma irracional son con vistas al

\footnotetext{
11 Trad. Vallejo Campos.
}

Stylos. 2021; 30 (30); pp. 124-136; ISSN: 0327-8859; E-ISSN: 2683-7900 
alma racional, es decir, que se subordinan al intelecto. La subordinación del cuerpo y de la parte irracional del alma a la parte racional se funda en un orden o jerarquía natural. Aquí el Estagirita sostiene que el intelecto constituye lo que es el hombre porque es la facultad que le permite cumplir con su función y fin propios del mejor modo posible (Fr. 63), a saber, la contemplación de la verdad (Fr. 65-70). ${ }^{12}$ Pero, por otro lado, afirma que el intelecto es la parte del alma con mayor autoridad para ejercer el gobierno de la conducta del hombre (Fr. 61). ¿Cómo entender esta combinación de aspectos teórico y práctico del intelecto?

En el Protréptico el término noûs no alude únicamente al intelecto teórico, puesto que se encuentra estrechamente emparentado no sólo con sophía y epistéme, sino también con phrónesis; términos que el Estagirita emplea indistintamente para referirse a la parte racional del alma. ${ }^{13}$ Deberemos esperar a la Ética Nicomaquea para la demarcación explícita de los aspectos teórico y práctico del intelecto.

En este contexto, la primacía del intelecto consiste no sólo en que constituye la parte esencial del hombre sino en que, en el plano de la acción, debe gobernar el cuerpo y el alma irracional. Puesto que la parte racional tiene por función el conocimiento, conoce el bien del cuerpo y del alma irracional, lo que fundamenta su gobierno sobre aquellos: es decir, la conducción del intelecto repercute en el cuidado y la realización de los fines propios del cuerpo y del alma irracional. Puesto que el compuesto humano es con vistas al intelecto, el gobierno racional del cuerpo y del alma irracional constituye la condición de posibilidad de la actividad distintiva del noûs, y del

${ }^{12}$ Cf.. C. Seggiaro (2019: 153-191). Para la autora, la concepción antropológica del Protréptico se encuentra signada por las nociones de physis y érgon: "para Aristóteles el cumplimiento de la naturaleza de una cosa se identifica con el ejercicio de su función propia" (2019: 90). En el caso del ser humano, este alcanza la plenitud cuando lleva a cabo su érgon propio (el intelecto) del mejor modo posible. La naturaleza se caracteriza por su carácter teleológico, y el érgon constituye lo que hace que algo sea lo que es (y no otra cosa). De acuerdo con el Fr. 63, el érgon consiste en el ejercicio de la función natural, y únicamente cuando se realiza de forma excelente constituye el bien y la virtud de la cosa. El bien de algo es aquello que es querido por sí mismo, es decir, su causa final y la realización de su naturaleza.

${ }^{13}$ En el Fr. 17, el Estagirita define phrónesis en los mismos términos que define noûs en los Frs. 23 y 24. Paralelamente, en los Frs. 33 y 35, equipara phrónésis con epistéme, cf. SEGGIARO (2019: 155).

Stylos. 2021; 30 (30); pp. 124-136; ISSN: 0327-8859; E-ISSN: 2683-7900 
hombre en su conjunto, esto es, la intelección. A continuación, procuraremos mostrar que esta tesis es conservada y desarrollada en el pensamiento aristotélico posterior.

Si bien en la Ética Nicomaquea se identifica el "sí mismo" con el noûs (IX. 4, 1166a10-19, IX. 8, 1168b15-23, X. 7, 1177a12-17), los especialistas discuten sobre qué aspecto del intelecto se basa dicha identificación. En otras palabras, algunos estudiosos consideran que en IX. 8 se identifica el "sí mismo" con el intelecto práctico, ${ }^{14}$ mientras que en X. 7 se lo identifica con el intelecto teórico. ${ }^{15}$ Para otros, el Estagirita no diferencia explícitamente entre ambos intelectos, puesto que constituyen dos funciones de una misma facultad. ${ }^{16}$

En la Ética, Aristóteles adopta los lineamientos principales de la segunda concepción platónica del "sí mismo", de acuerdo con la cual el alma se encuentra compuesta de partes diferentes que pueden ordenarse en armonía o en conflicto (según gobierne la parte racional o la irracional). Sin embargo, a diferencia de su maestro, el Estagirita no otorga el título de "sí mismo" a cualquier parte del alma, sino que limita dicha identificación al intelecto y, por extensión, al conjunto del alma gobernada por el noûs.

En el libro noveno Aristóteles afirma que el alma puede adoptar dos ordenamientos o configuraciones posibles, ${ }^{17}$ de acuerdo con las cuales podemos hablar de amistad o enemistad para con uno mismo (IX. 4. 1166a119, IX. 8. 1168b5-10): el orden armonioso implica concordia y colaboración entre las partes del alma bajo el comando del intelecto, de allí que podamos hablar de amistad para con uno mismo en el caso del alma del hombre virtuoso (EE VII. 6, 1240a13-23, 1240b1-4). En la configuración del alma viciosa, por el contrario, el intelecto riñe o se subordina a la parte irracional, de allí que el alma carezca de un orden racional y se encuentra en conflicto o enemistad consigo misma. El alma de los hombres viciosos se encuentra dividida por la lucha permanente entre intelecto y apetitos, es decir, se frag-

${ }^{14}$ Cf. ANNAS (1981: 3-4).

${ }^{15}$ Cf. COOPER (1980: 169-180).

${ }^{16}$ Cf. Kahn (1981: 30, n. 1), Majithia (2004:187), IrRera (2017: 56).

${ }^{17}$ Cf. Majithia (2004: 184-5). 
menta porque no hay unidad de deseo sino tendencias enfrentadas que la conducen en direcciones contrarias (IX 4, 1166b2-29).

Es importante destacar que el Estagirita niega que los viciosos posean un "sí mismo", pero no porque carezcan de intelecto: su racionalidad sigue el comando de la parte irracional del alma. Los viciosos adolecen de un "sí mismo" en el sentido de que carecen del orden virtuoso del alma, que se caracteriza por la unidad y la armonía. ${ }^{18} \mathrm{El}$ alma viciosa carece de unidad desde un punto de vista ético-psicológico, puesto que su "sí mismo" se divide en dos partes en conflicto. Los individuos virtuosos tienen un "sí mismo" porque su alma es gobernada por el intelecto, mientras que no podemos hablar de un estado psíquico similar en el caso de los viciosos porque su alma carecen de unidad y de mismidad. En otras palabras, los viciosos carecen de "sí mismo" en la medida en que la unidad de su alma se encuentra fracturada por conflictos internos, mientras que los virtuosos poseen un "sí mismo" unificado por el intelecto. ${ }^{19}$ En esta línea, el Estagirita se distancia de su maestro al restringir la identificación del "sí mismo" con un único ordenamiento del alma (el resultante del gobierno del intelecto por sobre la irracionalidad).

En suma, en el libro IX Aristóteles identifica el "sí mismo" con el intelecto práctico, cuya autoridad (kúrios) se basa en el dominio de la parte irracional. Sin embargo, esta caracterización no se condice con la identificación en el libro X entre noûs e intelecto teórico (1177a12-17). De este modo, se plantea una divergencia entre dos "sí mismos": el que gobierna la existencia propiamente humana, y el que rige la vida que intenta seguir lo más divino en el compuesto humano, el intelecto teorético (1177b26-1178a2). La vida humana corresponde al compuesto alma-cuerpo (1178a10-21), en la cual tiene lugar el conflicto entre las partes racional e irracional del alma,

\footnotetext{
${ }^{18}$ Cf.. STERN-Gillet (1995:18-19, 25-29), para quien la noción aristotélica de "sí mismo" no consiste en un concepto descriptivo sino normativo (el ideal de armonía entre las partes del alma).

19 Cf. Biss (2011: 126-7) correlaciona las disposiciones de los individuos con el autoconocimiento que pueden alcanzar. Puesto que en los viciosos carecen de disposiciones estables (ya que en su alma pugnan los deseos, impulsos y compromisos), el conocimiento de sí que pueden alcanzar de sí mismos es opaco e inconsistente. Por el contrario, los virtuosos actúan desde disposiciones estables y desde deseos armonizados racionalmente, de allí que sean los únicos que puedan conocerse a sí mismos.
}

Stylos. 2021; 30 (30); pp. 124-136; ISSN: 0327-8859; E-ISSN: 2683-7900 
mientras que la vida "divinizada" e "inmortalizada" consiste en la intelección de las formas, es decir, la vida contemplativa (1177a17-25, 1177b1921).

Pero, por otro lado, el propio Aristóteles también sostiene que el hombre virtuoso -que aspira a vivir de acuerdo con el intelecto teorético-, debe continuar manteniendo vínculos más mundanos para vivir contemplativamente (1178b1-7, 1178b33-35), es decir, que debe obrar de acuerdo con las virtudes éticas en la medida en que se encuentra sujeto a las limitaciones humanas (la corporalidad, la necesidad de bienes externos, la convivencia con otros seres humanos, etc.). También sostiene que la vida de acuerdo con las virtudes éticas es feliz de manera secundaria (1178a9-10), es decir, afirma que constituye una vía genuina de felicidad e insinúa que es compatible con la vida contemplativa. ¿En qué reside dicha compatibilidad? El individuo virtuoso no puede dejar de ejercer las virtudes morales que robustecen su intelecto práctico frente a los apetitos con miras a dirigir el alma en su conjunto. El gobierno del intelecto práctico constituye la unidad del alma y, por ende, del "sí mismo": en este sentido, es la condición de posibilidad de que el individuo humano viva de acuerdo con su parte más divina, es decir, de que el alma sea conducida por el intelecto en su función teorética. En otras palabras, vivir de acuerdo con el intelecto teorético es imposible si el alma no se ha constituido antes en una unidad bajo el comando del intelecto práctico.

En suma, en el Protréptico Aristóteles identifica el "sí mismo" con el intelecto porque constituye la parte del alma que permite al ser humano realizar su función propia, esto es, la intelección. Sin embargo, la realización de la vida contemplativa exige que el intelecto gobierne la conducta humana. Este ideario de vida platónico sobrevive en la Ética Nicomaquea, donde el Estagirita sí distingue explícitamente entre funciones o aspectos del intelecto: allí expone dos sentidos de "sí mismo": de acuerdo con el primer sentido, el "sí mismo" consiste en la totalidad del alma gobernada por el intelecto práctico, mientras que el segundo identifica el "sí mismo" con la totalidad del alma conducida por el intelecto teorético. Para Aristóteles la excelencia humana se realiza tanto en el plano de la prâxis como en la vida contemplativa: el "sí mismo" práctico se constituye a partir de la práctica de la virtud, que unifica el alma bajo el comando de la racionalidad. La constitución del 
"sí mismo" teórico, y su comando del alma presuponen la unidad alcanzada por el intelecto práctico. De allí que ambas concepciones del "sí mismo" no se encuentren desvinculadas sino integradas en una única concepción antropológica y ética. En este sentido, la conceptualización aristotélica del "sí mismo" en la Ética no contradice la concepción asumida en el Protréptico, sino que constituye una versión ampliada de la identificación del "sí mismo" con el noûs, es decir, una tesis sobre el ideal moral al que debe aspirar el ser humano.

\section{REFERENCIAS BIBLIOGRÁFICAS}

ANNAS, J., "Self love in Aristotle", The Southern Journal of Philosophy, 1981 72: 1-18.

ANNAS, J., "Self-Knowledge in early Plato", 111-138. En: D. O`Meara (ed.) Platonic Investigations, Cambridge University Press, 1985.

BIEDA, E., "Unidad y multiplicidad del alma en la República de Platón", Quaderni Urbinati di Cultura Classica. 2015 138: 89-116.

BISS, M., "Aristotle on Friendship and Self-knowledge: The Friend Beyond the Mirror", History of Philosophy Quarterly, 2011 28: 125-140.

CAPPElletTI, A. J., "El Alcibíades mayor y el núcleo de la antropología de Platón. En: Sobre tres diálogos menores de Platón, 9-36, Venezuela: Equinoccio, 1987.

COOPER, J. M., "Aristotle on Friendship", 301.340. En: A. O. Rorty (ed.), Essays on Aristotle's Ethics, Los Angeles: University of California Press, 1980.

FIERRO, M. A., "La deducción de las partes del alma de un conflicto de deseos en República IV", THÉMATA, 2007 38: 61-75.

FERRARI, G.R.F., "The three part soul", 165-201. En: Ferrari, G.R.F. (ed.), The Cambridge companion to Plato's Republic, Cambridge: Cambridge University Press, 2007.

IRRERA, E., "Other Selves in Action Similarity and Complementarity between Virtuous Persons in Aristotle's Theory of Friendship", Maia, 2017 69: 47-67.

Stylos. 2021; 30 (30); pp. 124-136; ISSN: 0327-8859; E-ISSN: 2683-7900 
MAJITHIA, R., "Self and Soul in Aristotle", Trascendent Philosophy, 2004 5: 181-206

KAHN, C., "Aristotle and Altruism", Mind, 1981: 90: 20-40.

RIDER, B. A., "Self-Care, Self-Knowledge, and Politics in the Alcibiades I", Epoché, 2011 15: 395-413.

RoBINSON, R., "Plato's separation of reason from desire", Phronesis 1971 16: $38-48$.

Seggiaro, C. M., La concepción de filosofía en el Protréptico de Aristóteles. Su posible influencia platónica, Buenos Aires: Teseopress, 2019.

SIEWERT, C., "Plato's division of reason and appetite", History of philosophy quarterly 2001 18: 329-352.

STALLEY, R.F., "Plato's argument for the division of the reasoning and appetitive elements within the soul", Phronesis 1975: 20: 110-128.

Stern-GILleT, S., Aristotle's Philosophy of Friendship, Albany: SUNY, 1995.

TABAKIAN, D. A., "Recepción y reformulación de la concepción platónica del "sí mismo" en la Ética Nicomaquea de Aristóteles", 191-214. En: Magnavacca, S., Santa Cruz, M. I., Soares, L. (eds.), Conocerse, cuidar de sí, cuidar del otro. Reflexiones antiguas y medievales, Buenos Aires: Miño y Dávila, 2017.

Stylos. 2021; 30 (30); pp. 124-136; ISSN: 0327-8859; E-ISSN: 2683-7900 